\title{
Erratum to: Fault controlled geochemical properties in Lahendong geothermal reservoir Indonesia
}

\author{
Maren Brehme $^{1} \cdot$ Fiorenza Deon $^{1} \cdot$ Christoph Haase $^{2} \cdot$ Bettina Wiegand $^{3}$. \\ Yustin Kamah $^{4}$ Martin Sauter ${ }^{3} \cdot$ Simona Regenspurg $^{1}$
}

Online veröffentlicht: 9.3.2016

(C) Springer-Verlag Berlin Heidelberg 2016

\section{Erratum to: Grundwasser-Zeitschrift \\ der Fachsektion Hydrogeologie \\ DOI 10.1007/s00767-015-0313-9}

In the original online published version of the article the presented Fig. 1 and Fig. 5 were incomplete for editorial reasons. This mistake was corrected online and in this print issue. We are very sorry for the mistake.

Please find the correct Fig. 1 and Fig. 5 as follows:

The online version of the original article can be found under doi:10.1007/s00767-015-0313-9.

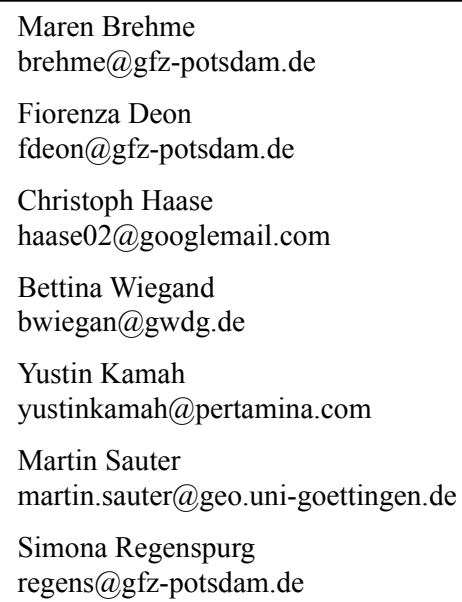

Helmholtz Centre Potsdam - GFZ German Research Centre for Geosciences, International Centre for Geothermal Research, Telegrafenberg, 14473 Potsdam, Germany

2 Institute for Geosciences, Kiel University, Ludewig-Meyn-Straße 10, 24118 Kiel, Germany

3 Applied Geology, University of Göttingen, Goldschmidtstraße 3, 37077 Göttingen, Germany

4 Upstream Technology Center Pertamina, Jl. Medan Merdeka Timur no. 6, Jakarta, Indonesia 


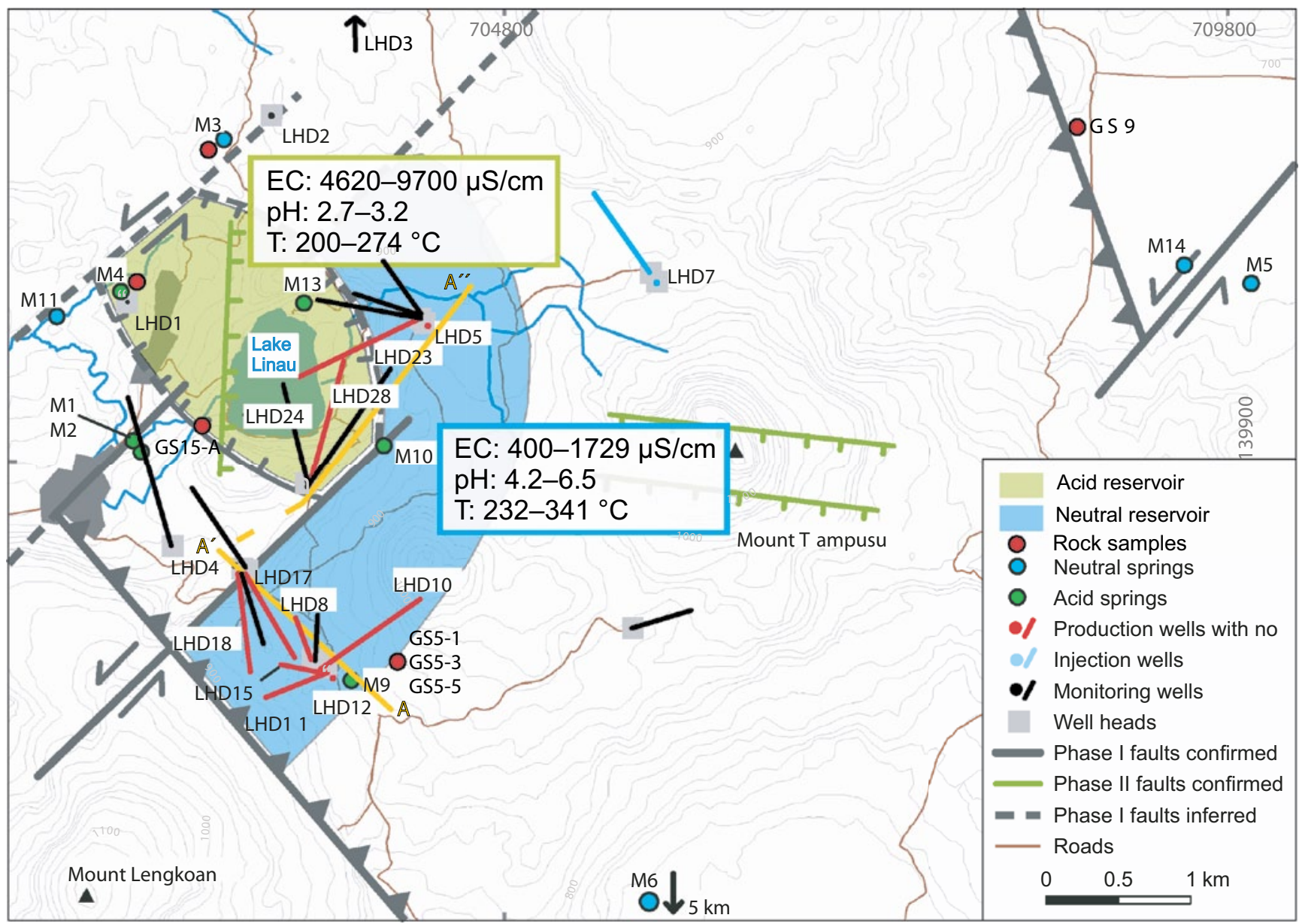

Fig. 1 Map of the study area with main faults and hydrochemical characteristics ( $E C$ electrical conductivity, $T$ temperature). Red, blue, and black lines indicate deviated wells. The yellow line shows the loca- tion of the cross section in Fig. 5. Water sample analyses are given in Tables 1 and 2 and rock sample analysis in Tables 3, 4, 5, 6, 7, 8 and Fig. 4 (modified from Brehme et al. 2014) 


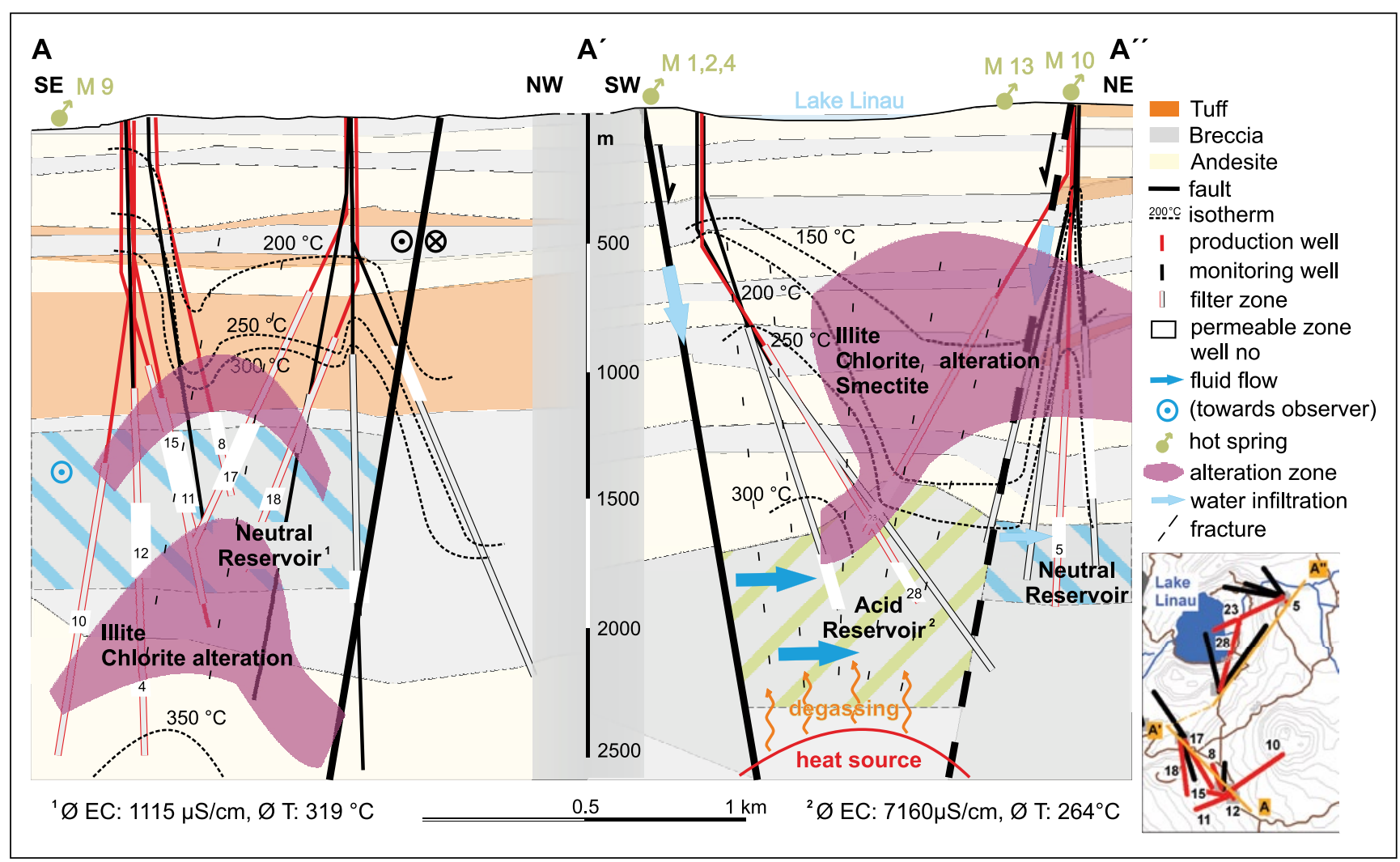

Fig. 5 Conceptual geochemical model of the study area, described by cross-sections with geological layering, fault location, temperature distribution, sample points and alteration patterns. For cross section line see Fig. 1 (modified after Brehme et al. 2014 and Utami 2011) 